\title{
In situ Liquid TEM Study for Degradation Mechanisms of Fuel Cell Catalysts during Potential Cycling Test
}

Shinya Nagashima ${ }^{1,5}$, Kenta Yoshida ${ }^{2,3}$, Tomoki Hiroyama ${ }^{2}$, Kun Liu $^{2}$, Yipu Kang ${ }^{2}$, Toshihiro Ikai ${ }^{4}$, Hisao Kato ${ }^{4}$, Tetsuo Nagami ${ }^{4}$ and Keisuke Kishita ${ }^{5}$

1. Materials Research and Development Laboratory, Japan Fine Ceramics Center, Atsuta-ku, Nagoya, 456-8587, Japan

2. Nanostructures Research Laboratory, Japan Fine Ceramics Center, Atsuta-ku, Nagoya, 456-8587, Japan

3. Institute for Advanced Research, Nagoya University, Chikusa-ku, Nagoya, 464-8603, Japan

4. Catalyst Design Department, Material Engineering Division, Toyota Motor Corporation, Toyota-cho, Toyota, Aichi, 471-8572, Japan

5. Material Analysis Department, Material Development Division, Toyota Motor Corporation, Toyotacho, Toyota, Aichi, 471-8572, Japan

The polymer electrolyte fuel cell (PEFC) is a promising energy source for fuel cell vehicles. The typical electrocatalyst used in PEFCs consists of platinum nanoparticles on carbon black (Pt/C). The development of advanced electrocatalysts for PEFCs requires reduction of Pt usage and enhancement of durability [1-3]. To achieve further design improvements for $\mathrm{Pt} / \mathrm{C}$ electrocatalysts, it is essential to understand the degradation mechanisms in real space for $\mathrm{Pt} / \mathrm{C}$ electrocatalysts.

We applied in situ liquid TEM observation technique using a liquid flow cell TEM holder with electrical biasing capabilities (Poseidon, Protochips Inc.) into the differential pumping environmental TEM (Titan ETEM, FEI Company) for direct observation of structural changes of $\mathrm{Pt} / \mathrm{C}$ electrocatalysts. The electrochemical cell simulating environment of activated PEMFC was comprised of deposited $\mathrm{Pt} / \mathrm{C}$ electrocatalyst onto an electrode on a MEMS chip and flowing electrolytic solution of $0.1 \mathrm{M}$ and $0.2 \mathrm{M}$ $\mathrm{HClO}_{4}$. We obtained cyclic voltammetry $(\mathrm{CV})$ curves by electrochemical measurement and dynamic TEM movies simultaneously.

Figure 1-3 are selected area captured (SAC) images of movies obtained from Pt/C electrocatalysts in $\mathrm{HClO}_{4}$ solution during potential cycling tests. We succeeded in direct observation of degradation behaviour of Pt/C electrocatalysts such as dissolution of Pt nanoparticles (Figure 1), detachment of a Pt nanoparticle from carbon support (Figure 2) and aggregation via Pt nanoparticles migration (Figure 3) which had been suggested [1-3].

In conclusion, in situ liquid TEM observation during potential cycling tests is a powerful tool for understanding of electrochemical behaviour of electrocatalysts of PEMFCs in nanometer scale.

References:

[1] Y. Shao-Horn, W. C. Sheng, S. Chen, P. J. Ferreira, E. F. Holby and D. Morgan, Top catal, 46, (2007), p. 285-305.

[2] X. Yu, S. Ye, Journal of Power Sources, 172, (2007), p. 145-154.

[3] J. C. Meier, C. Galeano, I. Katsounaros, A. A. Topalov, A. Kostka, F. Schüth and K. J. J. Mayrhofer, ACS Catal 2, (2012), p. 832-843. 


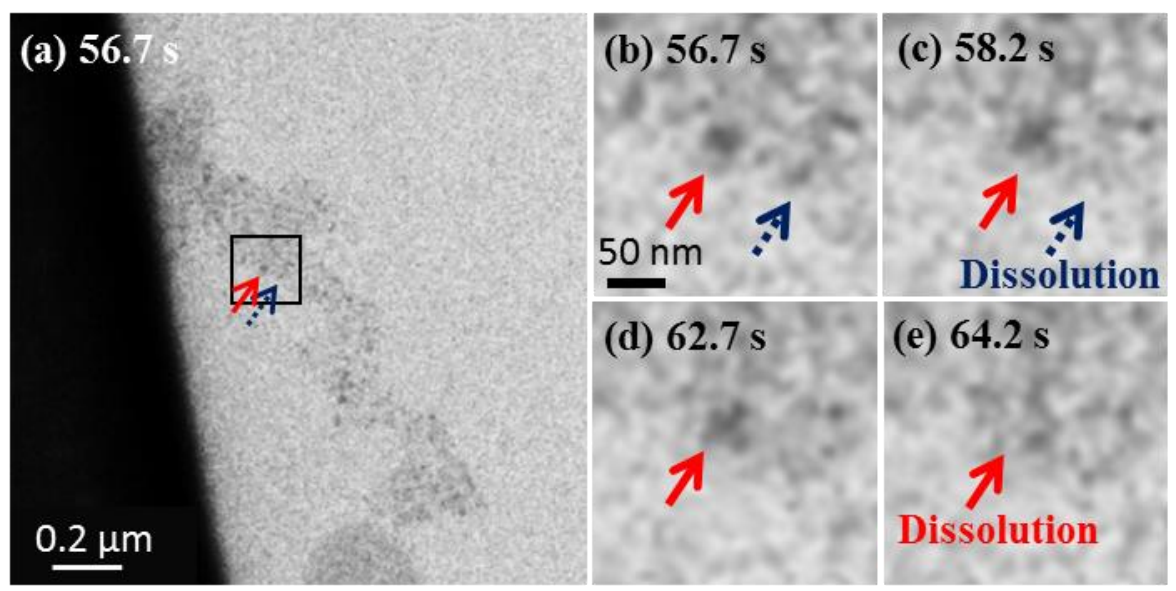

Figure 1. SAC images obtained from the $\mathrm{Pt} / \mathrm{C}$ electrocatalysts over the potential range from $-0.75 \mathrm{~V}$ to $0.30 \mathrm{~V}$ (vs. Pt) at a scan rate of $50 \mathrm{mV} / \mathrm{s}$ in $0.1 \mathrm{M} \mathrm{HClO}_{4}$ at room temperature.
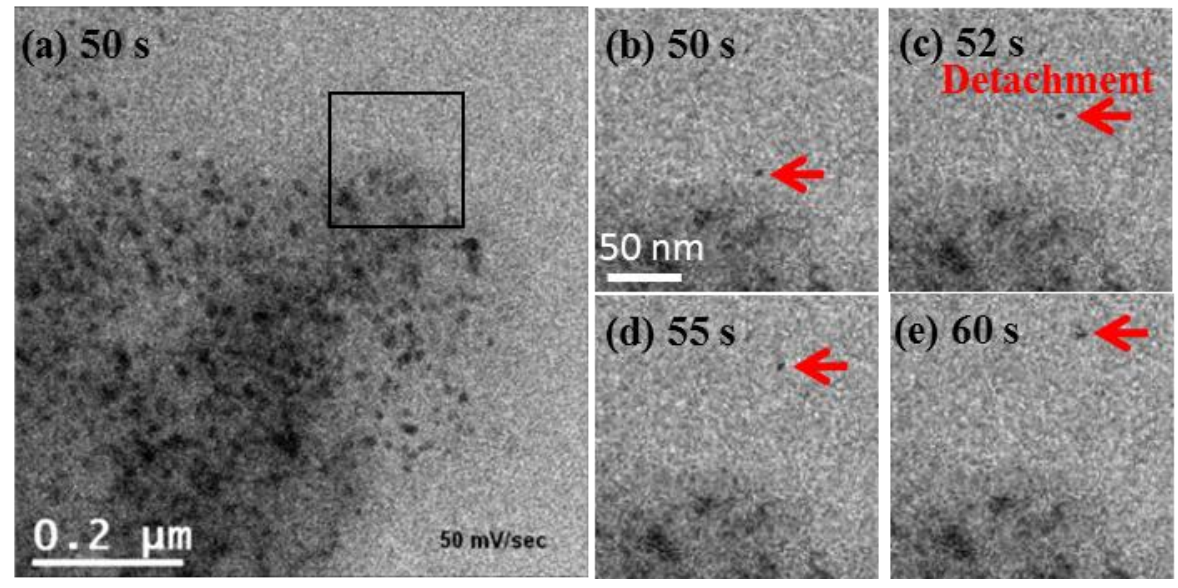

Figure 2. $\mathrm{SAC}$ images obtained from the $\mathrm{Pt} / \mathrm{C}$ electrocatalysts over the potential range from $-0.70 \mathrm{~V}$ to $0.45 \mathrm{~V}$ (vs. Pt) at a scan rate of $50 \mathrm{mV} / \mathrm{s}$ in $0.2 \mathrm{M} \mathrm{HClO}_{4}$ at room temperature.
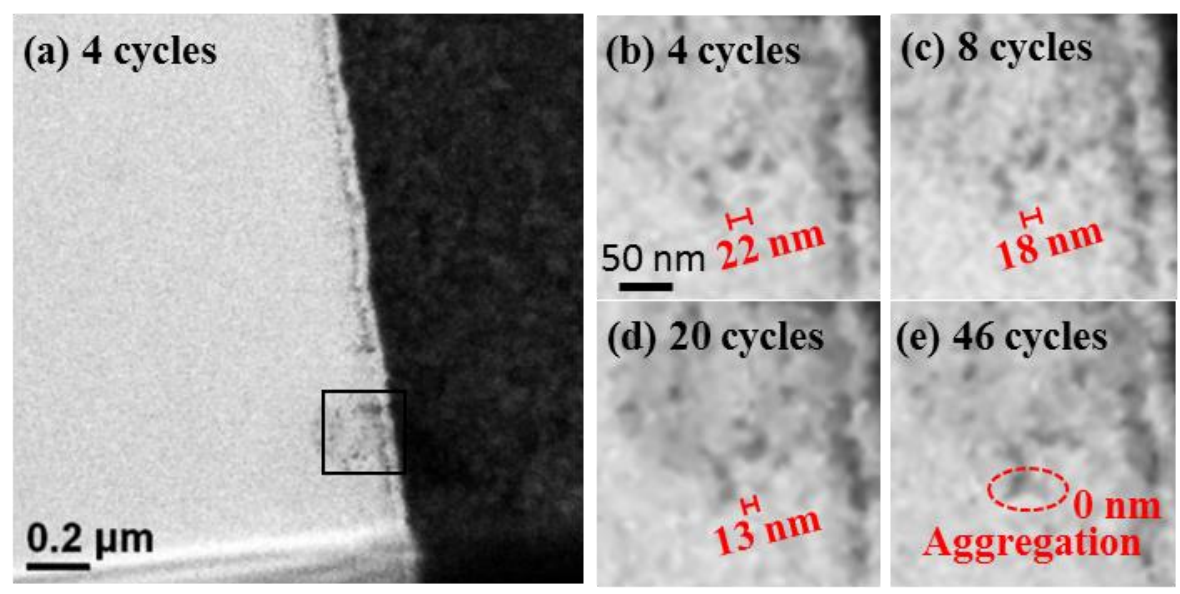

Figure 3. SAC images obtained from the Pt/C electrocatalysts over the potential range from $-0.70 \mathrm{~V}$ to $0.45 \mathrm{~V}$ (vs. Pt) at a scan rate of $500 \mathrm{mV} / \mathrm{s}$ in $0.2 \mathrm{M} \mathrm{HClO}_{4}$ at room temperature. 